\title{
An Action-Centred Approach to Conceptualising Information Support for Routine Work
}

\author{
Vivienne Waller \\ Department of Information Systems, University of Melbourne \\ email: vivienne.waller@unimelb.edu.au \\ Robert B Johnston \\ Department of Information Systems, University of Melbourne \\ email: robertj@unimelb.edu.au \\ Simon K Milton \\ Department of Information Systems, University of Melbourne \\ email: smilton@unimelb.edu.au
}

\begin{abstract}
In this paper, we continue our long-term project of developing a situated information systems analysis and design methodology, and present it as a radical alternative to conventional information systems analysis and design. Taking a situated approach entails focusing on action and a situated analysis and design methodology aims to increase efficiency and effectiveness through supporting routine action. We suggest that, as well as improving effectiveness and temporal efficiency, applying the situated methodology will result in less wasted human effort expended in search of information. We discuss the implications of an action focus for our conception of what an information system should be, and illustrate the application of the methodology with examples from a case study.
\end{abstract}

\section{Introduction}

Conventional information systems attempt to represent the real world (Weber, 1997). As the real world changes, the information system is updated. In other words, the information system enables tracking of state changes in the real-world system. As Weber points out:

... building, operating, maintaining, and observing the states of the information system must be less costly than observing the states of the 
real-world phenomena. Otherwise, there is little point to building the information system. We might as well observe the real-world phenomena directly (Weber, 1997).

In this paper, we present the case for a situated system, a radically different type of information system designed to support action in the world. Rather than attempting to represent the real world, the situated system informs actors when to do something and what to do without the need for recourse to a representation of the state of the world; the information is located 'in' the world and can be observed directly.

In previous publications (Johnston and Milton, 2002; Johnston et al., 2005) we have identified what we call the deliberative theory of action, which assumes that an actor uses a mental model of the world to decide what to do next. We have critiqued this theory of action, arguing that in routine action, actors respond directly to structures in the environment in order to attain goals. This alternative theory of action, the situated theory of action, informs our long-term project to develop an analysis and design methodology for situated information systems.

This paper is a conceptual output from the long term project of developing an analysis and design methodology based on the situated theory of action (Johnston and Milton 2002; Johnston et al., 2005; Milton et al., 2005). This program of research has proceeded by means of case studies. Two case studies have been conducted to inform the development of the methodology. These case studies have provided an opportunity to test our ideas and reflect on their practical application. The first case study is reported in Johnston et al. (2005), while the second case study is reported in Waller et al. (2006). Between the publications, there has been a gradual evolution in our understanding of the nature of the appropriate abstraction. Whereas the previous iteration of the methodology involved abstraction from work practices to goals and constraints, the methodology now focuses more explicitly on analysing action at multiple levels of abstraction. Hence, while reflection on the conduct of the case studies has helped refine our concepts, the concepts that we present are developed from a theoretical starting point rather than being entirely generated from or grounded in empirical data. Vignettes from the second case study are included to illustrate the theoretical points and to give examples of practical application of the methodology. Although these vignettes are from a case study conducted in a clinical setting, the methodology is for use to support routine action in any type of organisation.

We advance the project of developing situated systems by showing how a situated approach to systems analysis and design demands a focus on action. We then show how a focus on action leads to a different understanding of how best to provide information support. We explain how restructuring the environment and providing situated information to actors can enable routine 
conduct of actions, with lighter-weight information systems and increased efficiency and effectiveness. We draw on our insights into the nature of action and routine action to produce a new kind of information system analysis and design methodology, and we outline the principles of this situated systems analysis and design methodology as well as illustrate its application with examples from a case study. The methodology will be useful to organisations by allowing them to increase efficiency and effectiveness through supporting routine action. Unlike conventional information systems, as well as increasing temporal efficiency, situated systems also aim to increase human efficiency; in particular, to reduce wasted human effort expended in search of information. They can also increase effectiveness by preventing incorrect actions.

\section{Understanding actions}

The theory of actions underpinning our methodology is somewhat unconventional, drawing inspiration from the philosophical thinking of Johansson (1989) and Searle (1983). In the field of information systems, through the concept of a transaction, actions are traditionally conceptualised as causing changes in state, with the desired outcome being achievement of the goal state. We, however, eschew this idea that change can be understood as like a film strip of states of the world with action joining each frame. Instead we view the world through the dynamic lens of action itself and regard every action as simultaneously having both purposive (goal-like) and performative aspects.

The following expands on this understanding of actions. Of particular importance for the methodology are the following three properties of actions: that they are always situated in the environment, that they are multi-scale in nature and that they are dependent on the execution of other actions for instantiation as part of the action system. These properties are illustrated using material from the second case study of the project, conducted in a chemotherapy ward in a large hospital.

\section{The environment in which actions occur}

Structured information systems analysis and design methodologies tend to ignore the environment in which actions occur, representing actions as if they occur in a virtual space. In contrast, it is crucial to our analysis of action to take account of the environment in which actions occur. Consistent with our focus on action, we conceptualise the environment as all the actions available to an actor, that is, as the action possibility space. This means that if two different environments allow the same set of actions, they are equivalent for our purposes.

We analyse the environment in terms of structures in the environment that constrain or enable action. Gibson (1979) gave the name 'affordance' to the opportunities for action that structures in the environment provide to a particular class of actor. For example a chair affords sitting to a person; a hollow log may afford shelter to a small animal. Whereas Gibson focused on physical structures, 
the idea of affordance can be extended to temporal and organisational structures too. Physical structures include space, things and the arrangement of things. Organisational structures include roles and norms.

Every action is conducted by an actor in time and space, making use of resources. We define the actor, location, time and resources associated with an action as the action context. In other words, the action context is the particular dimensions of the environment in which a particular action occurs. The specifics of the action context mean that particular actions are constrained and enabled, depending on the affordances of the environment in which the particular time, place, actor and resources are located. The actors in whom we are most interested are human actors, although an organisation itself can be conceived as a macro actor performing actions.

Table 1 shows some of the actions undertaken as part of the administration of chemotherapy and the particular action context in which they occur. From the table it can be seen that a blood test can be taken in an external pathology lab, the hospital pathology lab, or the chemotherapy ward. It can be taken by pathology staff or a nurse using particular equipment to draw a sample of blood from a patient. Implicit in this is the idea that there are locations which are not suitable for taking blood, resources which can not be used to take blood, and actors who can not take blood. In other words, the action context indicates constraints on where, how and with what, blood can be taken. The action context also can provide clues about what action is to occur.

\begin{tabular}{|c|c|c|c|c|}
\hline Action & ACTION CONTEXT & & & \\
\hline & Location & Actor & Resources & Time \\
\hline $\begin{array}{l}\text { a. Sign } \\
\text { chemotherapy order }\end{array}$ & Hospital & Doctor & $\begin{array}{l}\text { Chemotherapy order } \\
\text { pen }\end{array}$ & $\begin{array}{l}\text { All of these are to be } \\
\text { done before patient }\end{array}$ \\
\hline $\begin{array}{l}\text { b. Approve chemo } \\
\text { orders }\end{array}$ & Hospital & Pharmacist & Chemotherapy order & $\begin{array}{l}\text { Actions a. and b. } \\
\text { need to be done }\end{array}$ \\
\hline c. Prepare treatment & Pharmacy & Pharmacy staff & Compounds, lab, etc & sufficiently before \\
\hline $\begin{array}{l}\text { d. Assess patient as } \\
\text { well enough for } \\
\text { treatment }\end{array}$ & Hospital & Nurse & \begin{tabular}{|l|} 
Blood results \\
Patient observations
\end{tabular} & $\begin{array}{l}\text { patient appointment } \\
\text { to allow treatment } \\
\text { preparation }\end{array}$ \\
\hline e. Give blood test & $\begin{array}{l}\text { External pathology } \\
\text { lab } \\
\text { Hospital pathology } \\
\text { lab } \\
\text { Chemo Ward }\end{array}$ & $\begin{array}{l}\text { Pathology staff } \\
\text { Nurse }\end{array}$ & $\begin{array}{l}\text { Syringe, etc } \\
\text { Patient }\end{array}$ & \\
\hline $\begin{array}{l}\text { f. Check blood test } \\
\text { results have arrived }\end{array}$ & Hospital & Hospital staff & Information system & \\
\hline $\begin{array}{l}\text { g. Analyse blood } \\
\text { results }\end{array}$ & Hospital & Nurse & Blood results & \\
\hline h. Take observations & Hospital & Enrolled nurse & $\begin{array}{l}\text { Thermometer, blood } \\
\text { pressure meter, etc }\end{array}$ & \\
\hline $\begin{array}{l}\text { i. Couch made } \\
\text { available }\end{array}$ & Treatment ward & Previous Patient & Couch & \\
\hline j. Patient is in ward & Chemo Ward & Patient & Transport to hospital & \\
\hline
\end{tabular}

Table 1: Actions and their context 


\section{Multi-scale nature of actions}

Actions are multi-scale in nature. This means that both actions and the action context can be specified at different levels of detail or grain size. Another way of saying this is that an action can be expanded into a set of lower level actions that occur in valid particularisations of the context of the higher action. For example, compare the following descriptions of the same action from Table 1:

'Gave a blood test'

Nurse applied the tourniquet to the patient's arm, spoke some words of reassurance to the patient, and inserted a syringe into a vein in the patient's arm. He raised the plunger of the syringe, withdrew it from the patient's arm and transferred the blood into two vials which he then labelled.

Johansson (1989) shows that actions have the peculiar trait of being 'temporally inclusive'. Roughly speaking, this means that each action can only be instantiated in time if those other actions that make up the action at a smaller grain size are instantiated within the duration of this action. For example, the duration of the action in which a blood test was given includes the duration of applying the tourniquet and the duration of inserting the syringe into the vein and withdrawing it full of blood. We suggest that this is a particular case of the more general case of the contextual inclusiveness of actions. For example, each action can only be instantiated in space if other actions (those that make up the action at a smaller grain size) are instantiated within the space of this action. This situational inclusiveness means that an actor is always simultaneously engaged in actions at all grain sizes. While inserting a syringe into a vein in the patient's arm, the Nurse is simultaneously taking a blood sample and giving a blood test.

\section{Action abstraction hierarchy}

We can understand this contextually inclusive relationship between actions of different grain size (in this case, inserting a syringe into a vein, taking a blood sample and giving a blood test) using Johansson's (1989) notion of an action abstraction hierarchy (here the term 'abstract' refers to abstraction away from particularities rather than meaning less 'real'). 


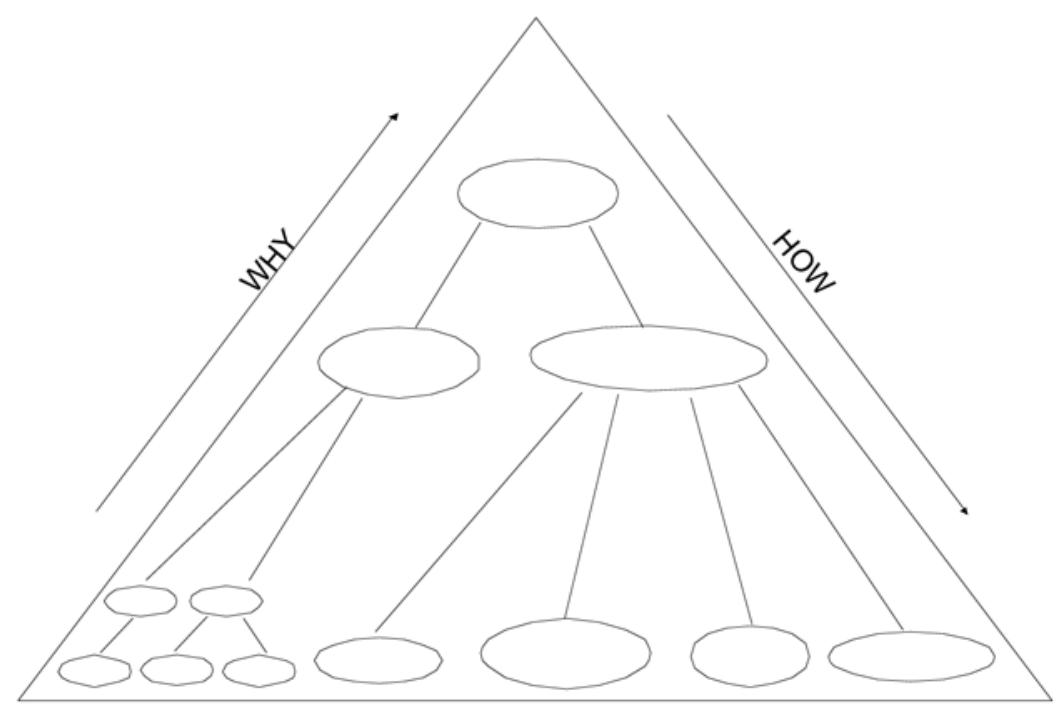

Figure 1: Action abstraction hierarchy: conceptual diagram of a system of actions.

The triangle in Figure 1 represents an action abstraction hierarchy in an action system, with the ellipses representing actions. Each action in the hierarchy refers to both the purpose and performance of action. Each action that is above other actions connected to it is the purpose of the action(s) below it; that is, it is why these subordinate actions are conducted. The collection of actions connected below the action is an elaboration of how the action is performed. This means that for any particular action, asking why that action is conducted moves one up the action abstraction hierarchy to more abstract levels. Asking how that action is conducted moves one down the action abstraction hierarchy to more concrete levels. The lower you go down the action hierarchy, the more is specified about the action context (that is, details of actor, location, time and resources). In other words, the action becomes more situated in a specific practice. By the same process, the implementation details of the higher-level action become specified more precisely as a set of more detailed actions.

As the hierarchy is ascended, the goal aspects of actions are emphasised; the performative aspects are emphasised in descent. In principle, each high level action could be specified with more and more precision as we move down the action hierarchy while the very apex of the triangle can be thought of as the ultimate purpose of the actions contained in the triangle. The triangle represents the domain space of all combinations of actions, actors, locations, resources and timing that will achieve the goal at the apex of the triangle. Note that the action abstraction hierarchy is an analytic device and the representation of it in two-dimensional space is indicative only rather than a precise rendering. 


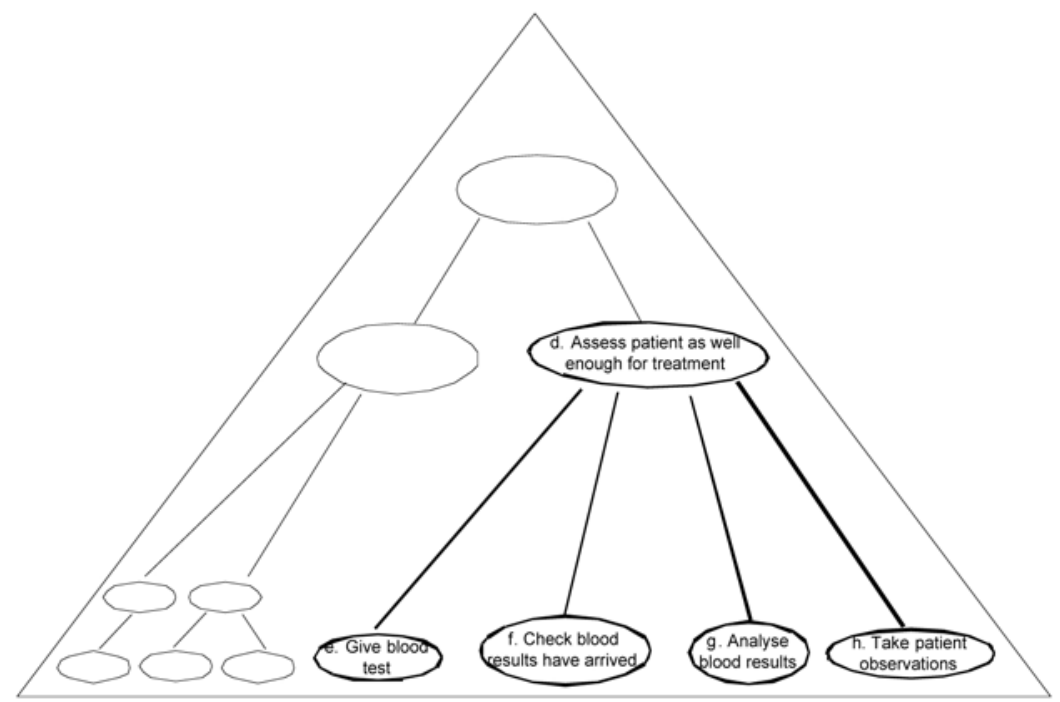

Figure 2: Action abstraction hierarchy: example from case study.

We can illustrate this abstraction/concretisation relationship between the actions listed in Table 1. For example, the actions, e. give blood test, $f$. check blood tests have arrived, $g$. analyse blood results and $h$. take patient observations, are all aspects of how the patient is assessed as well enough for treatment (action $d$ ). In turn, action $d$ is an expression of why actions $e, f, g$ and $h$ are performed. This is depicted in Figure 2.

\section{Action dependencies}

An action dependency is another type of relation between two actions. It describes the case when one action is dependent on completion of another action for instantiation as part of an action system. Whereas the vertical relationship in Figure 1 was conceptualised as 'why-how', this horizontal dependency relationship can be conceptualised as 'depends on/condition for'.

Figure 3 shows in bold the action dependencies of some of the actions shown in Figure 2. Actions on the right are dependent on the completion of those actions on the left, to which they are joined, for instantiation in the action system. This means that the actions on the right occur later in time than those actions on their left, to which they are joined. Note that what we call an action dependency relates to the rules of practice and is not necessarily the same as logical dependency or feasibility. It is quite feasible that hospital staff could check whether blood results have arrived before a blood test has been given; these hospital staff may not know the timing of the blood test. However, for this action to be part of the action system being described, checking that blood results have arrived depends on the blood test being given. Similarly, there is no a priori 
logical reason why analysing the blood results is dependent on someone checking that blood results have arrived. It may seem more logical to bypass this step altogether, notifying the nurse who analyses the blood results of their arrival. The point is that, in the action system this diagram describes, analysis of blood results was dependent on hospital staff checking that blood test results had arrived.

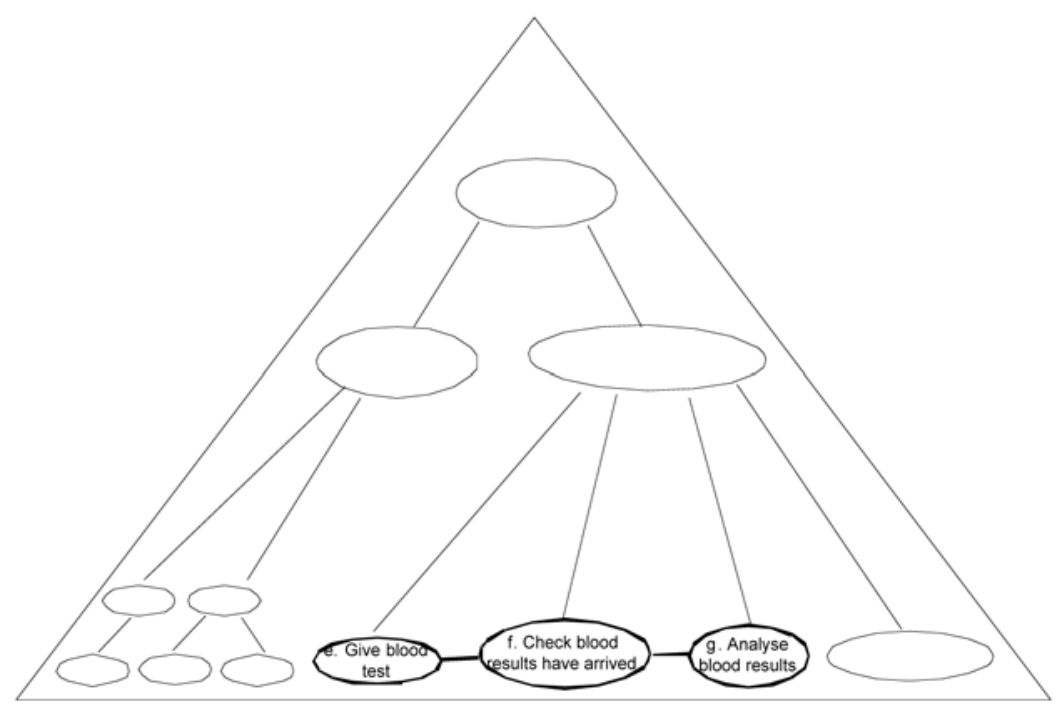

Figure 3: Action dependencies: some actions involved in administering chemotherapy.

\section{Efficiency and effectiveness of actions}

Having outlined our conception of actions, we now turn to what makes an action 'routine', relating routinisation of actions to increased efficiency and effectiveness. We start by defining what we mean by efficiency and effectiveness of actions.

\section{Efficiency of actions}

A common measure of efficiency is the minimisation of the expenditure of resources to achieve specified goals (Agerfalk and Eriksson, 2006). Bevan (1995) identifies three dimensions of efficiency. Although Bevan's work is about developing a measure for software quality, these dimensions are equally applicable to the characterisation of the efficiency of a system of actions. They are, firstly, temporal efficiency, or the minimisation of the expenditure of time; secondly, human efficiency, or the minimisation of mental or physical effort; and thirdly, economic efficiency, or the minimisation of financial cost.

One can measure the efficiency of the following three aspects of actions: 
- What action is done?

- How is the action done?

- When is the action done?

Note that because each action is itself comprised of lower order actions, the answer to the question 'How is the action done?' gives answers to the question 'What action is done?' lower down the action abstraction hierarchy. For example, for the action 'Communicate account number', the answer to the question 'How is the action done?' may be 'Look up record and read out number over the phone'. This description of how, 'Read out number over the phone', is the answer to 'What action is done?' further down the action abstraction hierarchy.

\section{Effectiveness of actions}

A standard measure of the effectiveness of something is whether or not it leads to achievement of the intended goals. Two aspects of effectiveness mentioned in the international standard ISO 9241-11 are completeness and accuracy (Agerfalk and Eriksson, 2006).

In the chemotherapy example four goals were identified, including administering chemotherapy and providing a high standard of patient care. High quality patient care included answering patient queries, and liaising with other health professionals involved in the patient's care, such as the dietician and social worker. Hence, in the chemotherapy example, completeness requires, not only that chemotherapy is efficiently administered, but also that nurses have time to attend to patients' other needs Accuracy entails correctly administering the correct dosage of the correct treatment to the right patient.

\section{Routinising action}

In order to act, an actor needs to select what to do next, how to do it, and when to do it. Another way of saying this is that in order to perform an action, an actor needs to know that action is feasible in the world (i.e. that they have the authority and skills to perform that action at the time, in the space, and with the resources at hand). The actor also needs to know that the action is possible now (i.e. that the action dependencies have been satisfied).

Routine action is characterised by the removal of discretion in the conduct of an action in one or more of the following aspects: what action is done, when the action is done and how the action is done. This is, however, removal of discretion at a meaningful grain size rather than the complete removal of discretion. Given a small enough grain size, there will always be some discretion in what, when and how an actor does something. For example, even if a doctor has to physically sign a chemotherapy order in order to authorise it, he or she has discretion over 
what sort of pen is used, how the pen is held, the exact form of the signature, and so on.

In later examples, we show how routinising action can improve the effectiveness and efficiency (economic, human and/or temporal) of action. Although temporal and human efficiency are related to economic efficiency, since time and people cost money, they are important aspects in their own right. Economic efficiency has always been an important driver of conventional information system design, and the importance of temporal efficiency is starting to be recognised (e.g. in JIT systems). However, the importance of human efficiency is often overlooked in conventional information systems. In situated analysis and design, we give explicit recognition to the cost of wasted human effort, including the human cost of unnecessary actions such as searching for information or resources.

Temporal efficiency is required for effectiveness in time-constrained environments; for example, a ward that has to administer chemotherapy to all patients during operating hours. Effectiveness is also increased by structuring the organisational and physical environment to limit the possibility for human error; that is, to avoid incorrect (and, in this case, possibly dangerous) actions.

\section{A situated approach to enabling routine action with information}

Conventional information systems provide information to actors through updating representations of states of the world. (Weber, 1997) As we have argued elsewhere (Johnston et al., 2005), this is because conventional information systems are based on the assumptions of a deliberative theory of action; that is, that an actor creates a mental model of the state of the world before acting. The conventional information system supplies information about the state of the world to inform the actor's mental model. The situated approach is based on our insights that information about the action context and the action dependencies are both necessary and sufficient for the actor to act routinely. Situated systems also use a form of representation to provide information to the actor but in their case it is the possibility for action that is represented in order to inform the actor about satisfaction of the action dependencies. However, whereas representation is the 'essence' of conventional information systems (Weber, 1997), situated systems enable routine action through manipulating the action possibility space to ensure that the action context is appropriate to the required action.

\section{Signals: representing the possibility for action}

We have shown that in an action abstraction hierarchy, the successful execution of an action is dependent upon the completion of the action or actions on which it is dependent. This means that in order to act, actors need to know that the actions on which their intended action is dependent have been successfully completed. Visual and/or aural information can indicate to the actor when this 
is so by representing the completion or result of the prerequisite action(s) or, more generally, by representing the possibility of the next action. For example, a green light may signal to an actor that they can proceed with an action.

\section{Manipulating the action possibility space}

We have discussed how the specifics of the action context mean that particular actions are constrained or enabled, depending on the affordances of the environment in which the particular time, place, actor and resources are located. Changing the affordances of the environment, through changing the physical, organisational, or temporal structures, can increase efficiency and can provide situated information to actors about what to do next and how to do it. It can also increase effectiveness by making incorrect and possibly dangerous actions impossible to perform.

For example, with regard to organisational structure, assigning a particular role to a particular class of actor circumscribes the actions available in a particular action context. In the workplace, this means that employees know that only certain types of employee can do certain things. It can also cause bottlenecks if the class of actor required to conduct a particular action is a scarce resource. Separating tasks into different time blocks is a way of structuring the temporal environment. This circumscribes the types of actions available in that time block and may increase human efficiency (Bevan, 1995) through reducing cognitive effort.

\section{Parsimonious systems}

The two approaches of representing the possibility of action, and manipulating the action possibility space, can be combined to yield lightweight information systems. For example, performing a network backup may require that all users have logged off but it is inefficient for the IT technician to have to make sure that each user has logged off. Instead, a temporal structure is imposed: users are told that they need to have logged off by $6 \mathrm{pm}$. The clock striking six represents completion of logging off by all users. This is a signal to the IT technician that the backup can be performed.

Hence, structures in the environment such as particular divisions of labour, physical layout, provision of tools, and timetables can enable and constrain particular actions as well as provide situated information to actors about what to do next and when and how to do it. The signals can be quite simple, even binary, and can be conveyed by the mere presence or absence of a token (icon, card, tone, light) in the environment.

We suggest that these situated systems are more compatible than conventional information systems with the human efficiency requirements of time-constrained environments. Simplifying the environment can reduce an actor's cognitive load 
as well as the physical effort of searching for information. As well as being parsimonious, we suggest that these systems are more reliable than conventional systems since the potential for human error is reduced.

\section{A methodology for situated analysis and design}

We have explained how restructuring the environment and providing situated information to actors can increase efficiency and effectiveness by enabling routine conduct of actions. Now we show how these insights can be combined to produce a new kind of information system analysis and design methodology. This methodology aims to increase efficiency and effectiveness through supporting routine action; in particular, by reducing wasted human effort in search of information.

\section{The domain of the situated analysis and design methodology}

\section{What actions can be routinised?}

Not all actions systems can be routinised in order to improve efficiency and effectiveness. It is a separate project to define exactly what the necessary conditions are, but basically we need to be able to describe the action dependencies. For example, it would not be possible to design a system of routinised actions to cure patients of cancer. This is because we do not know what set of actions will reliably cure patients of cancer. In other words, we cannot describe the action dependencies that will lead to a patient being cured of cancer.

\section{What actions should be routinised?}

Whether or not an action should be routinised is not evident from the description of the action, any more than whether or not an action is useful is evident from the description of the action. For example, even as apparently creative an activity as writing a song can be routinised through use of a template and formulas; indeed, many popular 'hits' have been written this way. Similarly, lecture preparation can be approached either as a routine or as a creative activity.

While the purpose of routinising an action is to increase efficiency or effectiveness or both, a good system takes account of more than this. The ISO standard criteria for usability of products (ISO 9241-11) are the effectiveness, efficiency and satisfaction with which users can achieve their goals. We will apply these criteria to the quality of systems, replacing the notion of 'user' of a system with that of 'actor' in the system. This means that, although the purpose of routinising an action is to increase efficiency or effectiveness, this needs to be weighed up against the effects on actor satisfaction. Returning to the previous examples, there are writers who do not want to approach song writing in a 
formulaic way. Similarly, there are lecturers who prefer to have complete discretion over how they prepare and present a lecture, perhaps even eschewing established conventions.

In any organisation, choosing which actions are to be routinised is a matter of negotiation between stakeholders, rather than being evident a priori. The issues at stake in deciding whether to routinise something are efficiency, effectiveness and actor satisfaction. Actors who gain satisfaction from relying on their professional skill and judgement to carry out particular actions may not wish to see these actions routinised. Which actions should be routinised also depends upon the specifics of the workplace. If routinisation does not significantly improve the efficiency or effectiveness of the action, then there is no reason to introduce a routine system simply for the sake of it. On the other hand, routinisation has the potential to greatly improve efficiency and effectiveness, particularly through reducing actions such as unnecessary searches for information.

\section{Applying the situated analysis and design methodology}

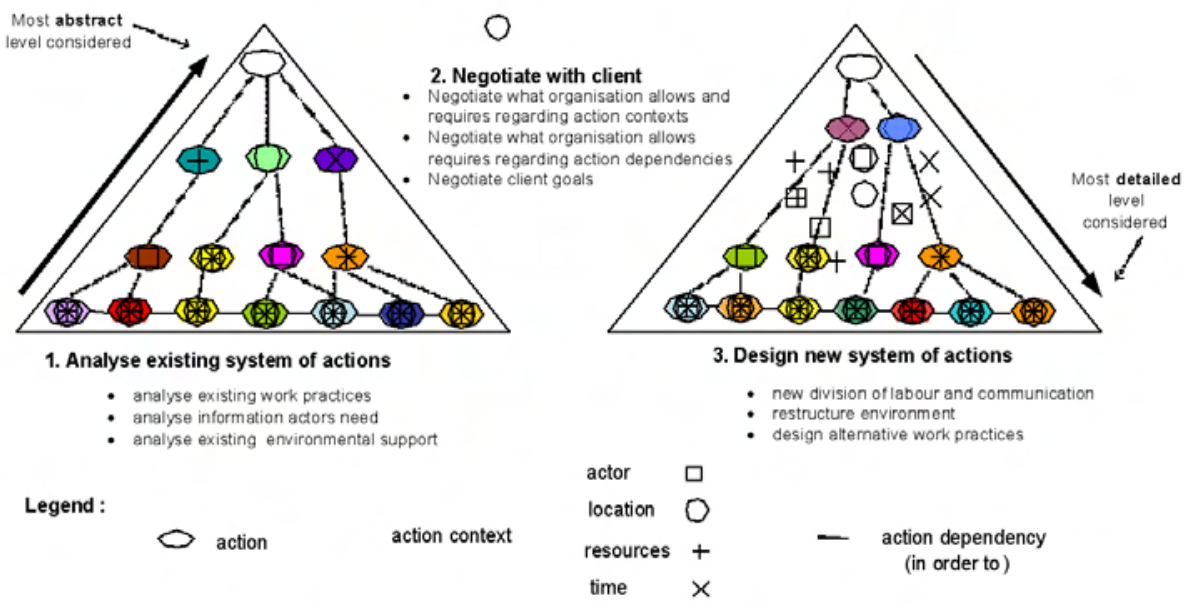

\section{Figure 4: Applying the situated analysis and design methodology.}

In this section, the principles of the methodology are outlined and illustrated using examples from the case study. Figure 4 is a conceptual depiction of the situated analysis and design methodology. As before, conceptually, each triangle represents a particular system of actions designed to achieve the goal(s) near the apex. The three stages in the methodology (represented as the triangles in Figure 4) are elaborated in the following sections. 


\section{Analysing the existing system of actions}

Analysis involves both description and evaluation. The existing system of actions is described in order to identify what is currently being achieved; at the same time, the efficiency and effectiveness of the existing system of actions is evaluated. There are three conceptually distinct aspects to the analysis of the existing system of actions: analysis of existing work practices, analysis of information actors' needs, and analysis of existing environmental support. In practice, these analyses may occur concurrently.

\section{Analysing existing work practices}

In principle, and as discussed above, each action could be specified with more and more precision as we move down the action hierarchy. In actual analysis we need only go down to the level of detail that is natural and makes sense to actors when describing what they do. Of course, the situated information system is only concerned with providing information about non-discretionary action. Those actions that are not to be routinised (because, for example, they depend on an individual's judgement and skill) are treated as black boxes in the analysis.

A variety of tools to describe action systems already exist (e.g. Peterson, 1981) and the choice of tool is not important to the methodology. Our emphasis is not on modelling tools but on conceptualising the processes of changing the existing system.

The basic principle is that existing work practices need to be analysed in terms of actions and their context; that is, what happens, when and where, who does it, and with what (see, for example, Table 1). These actions also need to be described in terms of their action dependencies (see, for example, Figure 3) and the purpose of each action needs to be established (see, for example, Figure 2). This last aspect goes beyond simple notions of modelling processes. It involves ascending the action abstraction hierarchy (asking 'why' questions) in order to understand, in increasingly general terms, the purpose of each documented action. At the same time, the particulars of the action context are also increasingly generalised.

Describing the action system in this way makes it possible to identify whether the sequence of actions (what), and the division of labour, use of resources, timing, and location (how) is efficient in terms of human effort and time. The analysis assists in identifying whether any actions are redundant and whether there is a need for better coordination (i.e. coordination of actions by particular people or things) as well as making explicit exactly where any delays are occurring.

The following example from the case study demonstrates an inefficient division of labour that resulted in a bottleneck. 


\section{Case study example 1: inefficient division of labour}

Before the pharmacy could prepare the treatment for a patient (individualised dosage of a drug), the patient's blood results needed to be checked and marked as OK on the chemotherapy orders. The liaison nurse had the job of checking the blood results and obtaining the chemotherapy orders for all patients to be treated for that day. However, the nature of the liaison nurse's job (liaising with doctors, nurses, patients, their carers, the pharmacist and other hospital staff) meant that she was constantly interrupted. This, in combination with the sheer numbers of patients to be checked meant that the liaison nurse tended to be a bottleneck in the process of chemotherapy preparation.

\section{Analysing information actors' needs}

In a system of actions, in order to act at the right time, actors need to know that the prior actions on which their action is dependent have been successfully completed. Analysis of the action dependencies reveals what information actors need in order to act. Both the human and temporal efficiency of actions can be improved by minimising the effort spent by actors looking for information; either information that required actions have been completed or information regarding which action is next. We return to the case study for an example where the existing system did not provide actors (nurses) with the information they needed at the time and place where they needed it.

\section{Case study example 2: information nurses need in order to administer chemotherapy to a patient}

In order to administer chemotherapy to a particular patient, nurses needed to know whether the patient had arrived, whether a treatment couch was available, whether the chemotherapy treatment had been prepared, and whether the patient was well enough for chemotherapy treatment. However, nurses were required to be physically by the side of the patients they were currently treating. While it was immediately (visually) obvious to a nurse when a treatment couch became available, information about whether the other conditions were met could only be obtained by leaving the side of the patient. A disproportionate amount of time was spent seeking this information, at the expense of attending to patient needs. The information sources that nurses used to find this information included the hospital mainframe computer system, inspection of the treatment table (where the chemotherapy treatments were brought after being made up in the pharmacy), visiting the waiting room and talking to the ward clerk. This meant that, while treating patients, nurses had to regularly walk into the treatment preparation room to check the treatment tables, walk to a computer to check the hospital computer system, or walk to the reception area to ask about particular patients, or to page a doctor. 
A further difficulty was that a patient might arrive just after a nurse had looked up the mainframe computer system, the treatment might arrive just after a nurse checked which treatments were in the treatment preparation room, or the blood results might become available just after a nurse had looked up the relevant computer system. Each of these time lags between the condition being satisfied and the nurse knowing that the condition was satisfied, contributed to an avoidable delay in administering the treatment and placed severe limits on the quality of patient care delivered. That is, it hampered effectiveness. As well as being spatially remote, the necessary information was not accessed in a timely way.

\section{Analysing existing environmental support}

In analysing the action context, to what extent existing environmental structures (physical, organisational and temporal) support action becomes evident. Paying attention to the affordances offered by existing environmental structures makes apparent whether efficiency could be improved through, say, altering existing roles or changing the spatial layout of the workplace or the temporal structure of the day. What follows is an example of how the physical location of a resource (the chemotherapy order) was not supporting routine action.

\section{Case study example 3: missing chemotherapy orders}

A patient's treatment and dosage was hand-written on a paper form called the 'chemotherapy order'. These chemotherapy orders were essential as an authorisation for treatment. They were kept in a sleeve inside the patient's paper history file, which frequently ran to several volumes. In theory, these histories for chemotherapy patients were meant to be brought up to the Chemotherapy Unit at least a day before the patients' chemotherapy treatments. In practice, some of these histories could not be located. If a patient had a downstairs clinic appointment before their chemotherapy appointment, the history (containing the chemotherapy orders) would be downstairs in the clinic and the patient would be expected to carry their history up to the Chemotherapy Unit after their clinic. On almost every day of the field research, there was at least one history that could not be located or chemotherapy orders were otherwise missing. Finding missing chemotherapy orders was a frustrating task involving much running around by clerks and nurses.

\section{Negotiations regarding the new system of actions}

In traditional information systems analysis and design, a requirements analysis is conducted to determine client needs in situated analysis and design, a negotiation phase occurs based around aspects of action; broadly, what is to be done and how it is to be done. 


\section{Negotiation of the action context and action dependencies}

Organisational constraints are those constraints to do with the specification of the action context and action dependencies; specifically, what is allowed and what is required by the organisation. Note that the constraints we refer to here are not the same as the structures in the environment that constrain or enable particular actions. Here we are referring to what is allowed and what is required by the organisation. What is allowed by the organisation is basically the set of actors, locations, times and resources that can be associated with action. A subset of these is what is required by the organisation. What is required by the organisation may be a reflection of the organisation's preferred way of operating or may be a response to outside pressures such as legislation. The organisation may have requirements regarding the action context. For example, the organisation may require that certain actions be conducted by a particular type of actor (e.g. a doctor), a particular instance of a type of actor (e.g. Doctor Jones), in a particular type of location (e.g. a hospital ward), a particular instance of a type of location (e.g. the chemotherapy ward), using a particular type of resource (e.g. expandable patient record), or a particular resource (e.g. written patient record), or any combination of these. The time may also be constrained. For example, chemotherapy treatments that take more than four hours to administer may have to be begun in the morning.

The organisation may also have some requirements regarding action dependencies; in other words, regarding the order of actions. For example, the organisation may require that treatment that has a short expiry is not prepared until chemotherapy orders are approved.

Nevertheless, some of what the organisation allows or requires will be negotiable, especially as some of the perceived requirements will simply be the way things have always been done. It is only in the negotiation phase that the analyst can identify which constraints are 'hard' (Johnston et al., 2005); that is, those that the organisation cannot or is unwilling to see changed. These 'hard' constraints are those constraints that necessarily govern aspects of any redesigned system; they are not negotiable with the client.

\section{Negotiation of client goals}

The client's goals for the system can be viewed as another type of 'hard' organisational constraint. Describing the existing system of actions included establishing the purpose of existing work practices. In other words, in terms of Figure 4, it involved moving up the action abstraction hierarchy. We make a pragmatic decision to move up the action abstraction hierarchy until we reach those actions the client considers are the goals. As well as describing the purpose of what is done, these higher-order actions become constraints on what is done. 
For example, through analysing the system of actions in the chemotherapy ward we identified four main goals in its day to day work. These are delivering chemotherapy treatment, providing a high level of patient-centred care, participating in clinical trials and nursing research and fulfilling the organisational administrative requirements. Each of these is a higher-order action performed by the client's organisation and is recognised by them as a goal. However, these are not necessarily the highest (most abstract) actions. We could use 'why' questions to move even further up the abstraction hierarchy. For example, chemotherapy is administered in order to treat a patient's cancer, in order to improve their health and so on. However, administering chemotherapy was a hard constraint in how the organisation treated a patient's cancer. This meant that there was no scope for us as analysts to consider other treatments such as, for example, alternative therapies.

As Figure 4 indicates, in the design phase, all organisational constraints that have been identified through negotiations as 'hard' are taken as given aspects of the new system of actions.

\section{Designing a new system of actions}

Designing a new system of actions involves taking account of hard constraints and making use of the action possibilities of the mix of possible actors, locations, resources and temporal ordering. In terms of Figure 4 this means moving down from the agreed goals, through the fixed context and dependency constraints and designing a new set of actions, dependencies and contexts that satisfy the agreed goals. The action possibility space is also deliberately manipulated to constrain and enable particular actions. The purpose is to increase efficiency and effectiveness through routinisation of action. Working within the hard constraints, use may be made of the affordances offered by existing environmental structures or the existing environmental structure may be changed in order to routinise the action.

Providing information to support routine action is also of key importance. Information is conveyed through representation of the possibility for action. This information assists actors not only to know what to do next but also gives them the information they need that allows them to do the next thing. In designing a new system, the action system need only be specified with enough precision so that actors know what they have to do.

The following example from the case study describes how a change in organisational structure and representation of the possibility for action supported routinisation of action. 


\section{Case study example 4: redesigning a new system of actions}

The proposed new system of actions included the following three solutions to problems identified in the analysis stage.

Change in organisational structure

As described earlier, analysis of existing work practices revealed that the liaison nurse tended to be a bottleneck in the process of chemotherapy preparation. A change in the organisational structure (division of labour) was recommended. Rather than having the liaison nurse check the blood results and obtain the chemotherapy orders for all patients, each treatment nurse was to check blood results and obtain chemotherapy orders for their own patients. This patient information was then in manageable parcels for each treatment nurse and it made sense that the treatment nurses obtain the information given that they were the ones who needed to use it. The shifting of more responsibility for patients to the treatment nurses was also welcomed by both the liaison nurse and the treatment nurses.

Representation of the possibility for action

Earlier in this section we described the wasted effort and delays caused by nurses having to seek out the information about whether the prerequisites for treating another patient were satisfied. The proposed solution was that Nurses carry devices to alert them in real time about the satisfaction of the prerequisites for patient treatment; that is when their patients arrive, when their patient's blood results arrive, and when the chemotherapy treatment is ready. In other words, the devices represented the possibility for action (the action of administering chemotherapy to a patient). Providing this information to nurses in the time and place in which they needed it, increased temporal and human efficiency.

Stabilisation of the physical environment (Hammond et al., 1995)

Again, earlier in this section, we described the wasted time and effort involved as clerks and nurses ran around trying to find missing chemotherapy orders. The proposed solution was that chemotherapy orders be taken out of the history files and stationed in DayWard. This greatly reduced the time spent searching for them.

\section{Relation to existing literature}

This section situates the approach taken in this paper in the relevant literature. Firstly, there are the theories of action that inspire the methodology. Accordingly, we summarise the relevant literature on action and the role of environmental structures.

Also relevant is the literature on other methodologies, with which situated analysis and design can be contrasted. We show that although situated analysis and design has some points of similarity with other ISAD methodologies, it is 
paradigmatically different from conventional methodologies, including business process reengineering. Situated analysis and design has more in common with less conventional methodologies such as soft systems methodology (SSM), Multiview, ETHICS, and cognitive work analysis. However, as the last part of this section shows, it is still quite a distinctive approach.

\section{Theories that situate action in the environment}

Our project draws theoretical inspiration from diverse areas of scholarly inquiry. The initial inspiration for a situated approach to information systems analysis and design came from Heidegger's existential phenomenology of being-in-the-world (Heidegger, 1961). Winograd and Flores (1986) explicitly drew on Heidegger to outline a new approach to design, as did Dreyfus (1999) in his critique of GOFAI (Good Old-Fashioned Artificial Intelligence). Both of these seminal works assisted in the conceptualising of an alternative kind of information system that did not require recourse to a representation of the world.

Although not necessarily using the term 'deliberative theory of action', the idea of situated action underpins work undertaken in artificial intelligence (Agre, 1997), robotics, (Brooks, 1991), distributed and situated cognition (Lave and Wenger, 1991; Hutchins, 1995; Clancey, 1997), animal behaviour (Hendriks-Jansen, 1996), and situated action itself (Suchman, 1987). All of this work is based around the idea that, in routine action, actors respond directly to structures in the environment to achieve their purpose. Within ecological psychology, the concept of affordance (Gibson, 1979; Heft, 2001) has provided a fuller account of the role of the environment in action, and more precisely, the role of environmental structures.

Studies of manual systems have also inspired the thinking behind the design of situated systems. For example, Mackay et al. (1998) describe how air traffic controllers use paper flight strips for landing planes. In this case the air traffic controllers use the flight strips to represent the possibility for action. Kanban is another type of manual system widely used in the automotive industry for the activity of replenishing parts for production (Schonberger 1987; Womack et al., 1990). In this case, Kanbans act as signals, with the meaning of the Kanban depending on its physical location. See Lederman and Johnston (2007) for other examples of manual systems that use signals and manipulation of the action possibility space to support routine action.

\section{Paradigmatic differences with structured ISAD methodologies}

Like situated analysis and design, business process reengineering (Hammer, 1990) pays attention to performance measures other than direct cost saving. In some ways, the situated analysis and design approach subsumes the approach of business process reengineering in providing a more general conceptual 
framework to identify opportunities to improve the efficiency and effectiveness of action.

However, business processes are not the same as actions. Data flows and processes do not refer directly to actions but rather the information consequences of actions. The concepts 'data flow' and 'process' are used in IS to refer to a whole cluster of ideas in the conventional approach, as articulated by (Weber, 1997), which are paradigmatically different to the situated approach. These ideas differ from the situated approach in two ways; the underlying theory of action and the underlying ontology.

The action-centred approach assumes that routine actions are a more or less direct response to the situations in which they occur. As argued previously, conventional approaches to ISAD are informed by a different theory of action that assumes that humans act after deliberation upon a mental model of the world (Johnston and Milton, 2001). In that tradition, processes are conceived in informational terms and what are essentially movements of data are taken to stand for the actions that create them. This is how processes are depicted in data flow diagrams (DFDs), for example. Situated analysis and design attempts to represent action directly whereas conventional descriptions of dataflow and processes are at one remove from the actual action.

Conventional tools such as DFDs are organised on the assumption that for every activity or action there is some sort of data flow. In other words, only activities that involve data flows really need to be modelled. However, in the situated approach, actions that do not involve data flows may still be important in describing what happens. For example, it was described in Case Study example 2 how nurses wasted a lot of time and effort checking whether blood results and the chemotherapy treatment had arrived. It was critical to the situated analysis and redesign to take account of these actions of checking, even though no data flows were involved. A conventional tool such as a DFD or process view would most likely model the presence or absence of the data (the data being the information consequence of blood results or chemotherapy treatment arriving). However, conventional tools may not capture the need to eliminate the effort of checking that the data had arrived.

With regard to the underlying ontology, according to the conventional view processes are manifest in data flows that convert inputs to outputs (Melao and Pidd, 2000). These data flows enable transition from one state of the world to another, with the aim being attainment of a particular goal state. According to the situated (and action-centred) view presented here, goals are the purpose of actions, and different actions can be grouped (and arranged in an action abstraction hierarchy) if they have a common purpose. 


\section{Relationship with other ISAD methodologies}

Checkland and Holwell (1998) have described soft systems methodology (SSM) as 'a set of principles of method rather than a precise method'. Situated analysis and design also fits this description and shares, with SSM, a broad concern with providing information in support of action. However, whereas situated analysis and design is concerned with routine action, SSM is concerned with ill-defined problem situations. Although the terms appear similar, the 'activity systems' of SSM are quite different from the 'action systems' of Situated Analysis and Design. The activity systems of SSM are conceptual and may bear little relation to actions in the real world (Checkland and Holwell, 1998). In contrast, the action systems of situated analysis and design are descriptive of the actions actually undertaken in the organisation.

The ETHICS methodology of Mumford (1983) entails a participatory design approach to systems analysis and design, with particular attention paid to job satisfaction. Situated analysis and design shares, with ETHICS, an appreciation of the importance of implementation issues as well as the view that technology must be appropriate to the organisation. The two approaches are not incompatible and it is conceivable that situated analysis and design could be conducted within an ETHICS framework. While ETHICS focuses on the organisational processes involved in systems analysis and design, situated analysis and design focuses on the analytic processes. In order to conduct situated analysis and design using an ETHICS framework the former would be conducted using the organisational process of participatory design. Job satisfaction would be negotiated as a 'hard' constraint.

Like situated analysis and design, Multiview (Avison and Fitzgerald, 2002) also explicitly includes attention to implementation issues and the relationship between the social and the technical. However, Multiview presupposes a computerised solution. Moreover, the analysis techniques used in Multiview (i.e. both Multiview 1 and Multiview 2) are quite different from the situated analysis and design focus on situated action. Multiview 1 analyses information needs using conventional data flow and entity models while Multiview 2 uses Object-Oriented analysis.

Finally, in some respects the abstraction action hierarchy used in situated analysis and design is similar to that advocated in cognitive work analysis (Rasmussen and Pejtersen, 1995; Vicente, 1999). Both involve abstraction away from the details of existing work practices to goals in order to facilitate redesign. However, situated analysis and design is more explicitly centred around action and the intention of situated analysis and design is to support routine operational activity whereas cognitive, decision-making activity is typically the focus of cognitive work analysis. Cognitive work analysis involves reengineering the physical 
surroundings; no consideration is given to altering the organisational or temporal environment.

\section{Conclusions}

The purpose of this paper has been to outline what a methodology for analysing and designing information systems would look like if it were focused on action. We have identified the following three important aspects of actions and these form the basis of our intervention.

- Actions are multi-scale in nature.

- Actions are always performed in an action context; that is, actions are conducted by an actor in time and space, making use of resources.

- Actions are dependent on the execution of other actions for instantiation as part of an action system.

In order to act, an actor needs to know what to do next, how to do it and when to do it. Another way of saying this is that in order to perform an action, an actor needs to know that the action is feasible in the world (i.e. that they can perform that action at the time, in the space, and with resources at hand). The actor also needs to know that the action is possible now (i.e. that the action dependencies have been satisfied). Hence, information about the action context and the action dependencies are both necessary and sufficient for the actor to act routinely.

Our approach to information system design makes use of these two points of leverage. We manipulate the action possibility space to ensure that the action context is appropriate to the required action. By representing the possibility for action, we inform the actor about satisfaction of the action dependencies and signal that they can act now. Our approach leads to a different view of what information is and how best to support action. This points the way to future work on a precise definition of what constitutes an information system.

We suggest that the methodology will be useful to organisations by allowing them to increase efficiency and effectiveness, through supporting routine action, which is generally marginalised in conventional IS methodologies. Unlike conventional information systems, as well as increasing temporal efficiency, situated systems also aim to increase human efficiency; in particular, to reduce wasted human effort expended in search of information. They can also increase effectiveness by making incorrect and possibly dangerous actions impossible to perform. Through the designs we have produced in the project case studies (Johnston et al., 2005; Waller et al., 2006), we have already provided evidence that systems designed using the situated analysis and design methodology are likely to be more lightweight than those designed using conventional methodologies. 
As well as being of practical significance, the methodology is theoretically important as it articulates for the first time what many experienced practitioners know tacitly: it is necessary to be sensitive to the importance of action. In addition, the situated analysis and design methodology provides theoretical support for the practical application of ubiquitous computing and this is something that we will be investigating further in future research.

\section{References}

Agerfalk, P. and Eriksson, O. 2006, 'Socio-instrumental usability: IT is all about social action', Journal of Information Techology, vol. 21, pp. 24-39.

Agre, P. 1997, Computation and Human Experience, Cambridge, Cambridge University Press.

Avison, D. and Fitzgerald, G. 2002, Information Systems Development: Methodologies, Techniques and Tools, 3rd ed., England, McGraw Hill.

Bevan, N. 1995, 'Measuring usablity as quality of use', Software Quality Journal, vol. 4, no. 2, pp. 115-50.

Brooks, R. A. 1991, 'Intelligence without representation', Artifical Intelligence, vol. 47, no. 1-3, pp. 139-59.

Checkland, P. and Holwell, S. 1998, Information, Systems, and Information Systems', Chichester, John Wiley and Sons.

Clancey, W. J. 1997, Situated Cognition: On Human Knowledge and Computer Representation, Cambridge, Cambridge University Press.

Dreyfus, H. L. 1999, What Computers Still Can't Do: A Critique of Artificial Reason, Cambridge, MIT Press.

Gibson, J. 1979, The Ecological Approach to Visual Perception, Boston, Houghton Mifflin Company.

Hammer, M. 1990, 'Reengineering Work: Don't Automate, Obliterate', Harvard Business Review, vol. 68, no. 4, pp. 104-12.

Hammond, K., Converse, T. and Grass, J. 1995, 'The stabilisation of environments', Artificial Intelligence, vol. 72, pp. 305-27.

Heft, H. 2001, Ecological Psychology in Context: James Gibson, Roger Barker, and the legacy of William James's Radical Empiricism, New Jersey, Lawrence Erlbaum Associates.

Heidegger, M. 1961, Being and Time, New York, Harper and Row.

Hendriks-Jansen, H. 1996, Catching OurselvesiIn the Act: Situated Activity, Interactive Emergence, Evolution, and Human Thought. Cambridge, The MIT Press.

Hutchins, E. 1995, Cognition in the Wild, Cambridge, The MIT Press. 
Johansson, I. 1989, Ontological Investigations: An Inquiry into the Categories of Nature, Man and Society, London, Routledge.

Johnston, R. B. and Milton, S. K. 2001, 'The significance of intentionality for the ontological evaluation of information systems', Proceedings of the 7th Americas Conference on Information Systems, Boston, MA, pp. 19806.

Johnston, R. B. and Milton, S. K. 2002, 'The foundational role for theories of agency in understanding of information systems design', Australian Journal of Information Systems, vol. 9, Special Issue, pp. 40-9.

Johnston, R. B., Waller, V. and Milton, S. K. 2005, 'Situated information systems: Supporting routine activity in organisations', International Journal of Business Information Systems, vol. 1, no. 1/2, pp. 53-82.

Lave, J. and Wenger, E. 1991, Situated Learning: Legitimate Peripheral Participation, Cambridge, Cambridge University Press.

Lederman, R. and Johnston, R. B. 2007, 'Are routine manual systems genuine information systems?', in Hart, D. and Gregor, S. (eds), Information Systems Foundations: Theory, Representation and Reality, ANU E-Press.

Mackay, W. E., Fayard, A.-L., Frobert, L. and Medini, L. 1998, 'Reinventing the familiar: Exploring and augmented reality design space for Air Traffic Control', Proceedings of Computer Human Interation (CHI'98), Los Angeles, CA.

Melao, N. and Pidd, M. 2000, 'A conceptual framework for understanding business processes and business process modelling', Information Systems Journal, vol. 10, pp. 105-29.

Milton, S. K., Johnston, R. B., Lederman, R. M. and Waller, V. 2005, 'Developing a methodology for designing routine information systems based on the situational theory of action', Proceedings of the13th European Conference on Information Systems, Regensburg, Germany.

Mumford, E. 1983, Designing Human Systems for New Technology: The ETHICS Method, Manchester, Manchester Business School.

Peterson, J. L. 1981, Petri Net Theory and the Modelling of Systems, New Jersey, Prentice-Hall.

Rasmussen, J. and Pejtersen, A. 1995, 'Virtual ecology of work', in Flasch, J., Hancock, P., Caird, J. and Vicente, K. (eds), Global Perspectives on the Ecology of Human-Machine Systems. Hillsdale, NJ, Lawrence Erlbaum Associates, pp. 121-156.

Schonberger, R. J. 1987, 'The Kanban System', in Voss, C. A. (ed.), Just-in-Time Manufacture, IFS (Publications), pp. 59-72. 
Searle, J. 1983, Intentionality, Cambridge, Cambridge University Press.

Suchman, L. A. 1987, Plans and Situated Actions: The Problem of Human Machine Communication, Cambridge, Cambridge University Press.

Vicente, K. 1999, Cognitive Work Analysis: Toward Safe, Productive, and Healthy Computer-Based Work, Mahwah, N.J, Lawrence Erlbaum Associates.

Waller, V., Johnston, R. B. and Milton, S. K. 2006, 'Development of a Situated Information Systems Analysis and Design methodology: a health care setting', Proceedings of the European and Mediterranean Conference on Information Systems, Alicante, Spain.

Weber, R. 1997, Ontological Foundations of Information Systems, Melbourne, Coopers and Lybrand.

Winograd, T. and Flores, F. 1986, Understanding Computers and Cognition: A New Foundation for Design, New Jersey, Ablex Publishing Corporation.

Womack, J. P., Jones, D. T. and Roos, D. 1990, The Machine That Changed the World, New York, Rawson Associates. 